\title{
A Study of Inflation Dynamics in India: A Cointegrated Autoregressive Approach
}

\author{
Rakesh Kumar \\ Assistant Professor, Department of Post Graduate Studies, \\ Punjabi University Regional Centre, Bathinda (Punjab)
}

\begin{abstract}
This study explores the inflation dynamics after following new economic policy in Indian economy by employing Restricted Vector Autoregressive technique. Inflation variable has cointegrating relationship with other macro economic variables. Money supply turned out to be most important variable in explaining the variation in inflation overtime followed by import index variable. IIP has inflation discouraging affect. Besides, apart from the economic variables, moral suasion factor has also been proved to be important in controlling Indian inflation. Cointegrating relationship among the variables has considerable bearing on the inflation dynamics. Moreover, inflation bears stable and correcting relationship with CPI and import index variables, however such relationship is unstable and explosive with money supply and IIP.
\end{abstract}

Key Words: Inflation, Policy Shocks, Cointegration, Granger Causality, Vector Error Correction

\section{Introduction}

Inflation is a very complex and complicated phenomenon in a developing country like India (Deshpande and Sarkar, 1995). For, it has been determined by the multiplicity of factors that are inter-related in an intricate manner (Patra \& Partha, 2010). The policy makers face a daunting task to control inflation of such manner. Money in circulation is increased, as a policy matter, to meet the growing need of the economy but it is most likely reflected in higher inflation due to disequilibrium with other macro economic variables. Besides, this has been proved in the literature of monetary economics that money supply bears a direct and positive relationship with inflation (Fisher, 1911). High level of economic growth, as experienced by the Indian economy in recent years, enhanced purchasing power of people, hence, fueling inflation. However, economic growth increases the supply of goods and services with the price reducing effect. Indian economy is more exposed to the rest of the world, and price shifts in the world economy is instantaneously reflected in Indian economy (Janak et.al. 2008). In globalized era, domestic efforts, sometimes, do not fructify due to factors beyond the control of policy makers. High rate of inflation levels distort the investment and consumption decisions (Hellerstein, 1997) and lack of holistic approach towards control of inflation may lower output and consequently, augment the unemployment problem.

Therefore, it is imperative understand the inflation dynamics to control the menace of inflation and establish macroeconomic stability. Present paper is an attempt to comprehend such multifaceted relationships in the Indian set up that may help the policy makers to decide about policy shocks.

\section{Literature Review}

An immense body of literature is available on inflation which concentrates on the dynamics of inflation in developing countries. Some of them had employed the structural approach to inflation while others follow the monetarist approach. The present study reviews a few prominent studies among them.

Pandit (1993), viewed that Indian government was placing excessive emphasis on the demand pull factors and was overlooking the cost push. The paper established that contractionary fiscal and monetary policies, even if effectively implemented, are not a good substitute for efficient resource utilization. Rather, it may hurt the economy and results in stagnation, at least in the short run.

Gary (1995) studied the inflation of Nigeria for the period between 1960 and 1993 by employing cointegration and error correction technique. The study concluded that monetary expansion explained the large degree of inflationary process in Nigeria. Besides, devaluation and agro-climatic conditions were also important. Lim \& Papi (1997) examined the major determinants of inflation in Turkey for the period between 1970 and 1995. Johansen's cointegration approach resulted that money supply, wages, export and import prices have positive influence on the domestic price level. However, exchange rate exerts inverse effect on the domestic price levels in turkey.

Domac \& Carlos (1998) investigated the behaviour and determinants of inflation in Albania. The results of Granger Causality tests indicated the M1 and the exchange rate have an important predictive content 
for almost the entire individual items of the CPI. The results of Cointegration and error correction technique confirmed that, in the long run, inflation is positively related to the real income.

In view of the fact that the Reserve Bank of India (RBI) has shifted from monetary targeting to a multiple indicator approach Callan and Chang, (1999), assess as to which indicators provide the most useful information about future inflationary trends. Employing a VAR framework in the empirical analysis, the paper concluded that while the broad money target had been de-emphasized, developments in the monetary aggregates remain an important indicator of future inflation. The exchange rate and import prices are also relevant, particularly for inflation in the manufacturing sector.

John (2003) used post liberalization data to study the causality between monetary aggregates and exchange rates. The paper employed a Vector Autoregressive (VAR) framework to find out as to which monetary aggregate explains the inflation in a better way. Even though no clear evidence is found as to which of the monetary aggregates best explains inflation. But from the VAR model, there is sufficient reason to believe that the broad money measure (M3) is better.

Bishnoi and Koirala (2006) studied the robustness and stability of inflation models in Nepal, a test of cointegration between inflation and its explanatory variables was used to find the long- term relationship among them and the Error Correction Mechanism (ECM) was used to find the short term relationship. The paper established that there was long period cointegrating relationship among relevant variables and ECM results revealed that of inflation was stable and robust.

Srinivasan et.al. (2006), estimated an augmented Phillips curve to examine the effect of supply shocks on inflation in India. In an Ordinary Least Square framework it was found that supply shocks have only a transitory effect on both headline inflation and core inflation. Moreover, the paper concludes that monetary policy in India is more focused towards the core inflation.

Mosayed \& Mohammad (2009) examined the determinants of inflation in Iran for the data from 1971-2006. The study adopted Autoregressive and Distributed Lag (ARDL) model and concluded that money supply, exchange rate, gross domestic product, changes in domestic prices and foreign prices are positively contributing to the domestic prices in the Iran.

Sahadudhen I (2012) studied the determinants of inflation of India on the quarterly data (1996 Q1 to 2009Q3) by employing the cointegration and Vector Error Correction model. It has been established that GDP and broad money have positive effects on inflation. However, inflation is negatively affected by exchange rate and interest rates.

\section{Objectives of the Study:}

1. To examine the nature and duration of relationship of inflation with other macroeconomic variables.

2. To study the short term behaviour of relevant variables in terms of their tendency to converge towards the cointegrating (long period stable) relationships.

3. To discern the importance of variables under consideration in explaining the variations in inflation level overtime.

\section{Variables, Data Base and Methodology: \\ Variables:}

Consumer Price Index (CPI), most comprehensive measure of inflation has been used to measure inflation. This study is based on the monthly data and best measure of demand in the economy is GDP, however, this measure is not available on monthly bases. Index of Industrial Production (IIP) holds strong positive correlation with the GDP. Therefore, IIP has been used as a representative for the volume of demand in the economy. It has been proved in the literature of monetary economics that money circulation has direct bearing on the levels of prices in the economy. Hence, broad money (M3) as measure of money supply has been used. In the era of globalization, exposure to the outer world has increased considerably. Consequently, the level of prices in the trading partners matters considerably for the domestic economy. To measure the external influence on internal prices has been represented by levels of Import Indices (IMP).

\section{Data Base}

This Study covers the period of January 1, 1992 to December 31, 2012. This period encompasses high as well as moderate inflation, hence; represent adequate variation in the data. In order to investigate the inflation dynamics monthly data series on the relevant variables are used. The data on relevant variables is culled from the official websites of Ministry of Statistics and Policy Implementation (www.mospi.gov.in) and RBI (www.rbi.org.in). In the present study M3 variable has been used in logarithm form and other variables (CPI, IIP, and IMP) are used in index format. The base year for the indices is 2004-05. 
Methodology

Granger Causality: The Granger Causality provides information regarding unidirectional or bidirectional relationship between variables.In order to test for Granger causality between one variable with the other variable, following equations are estimated;

$$
\begin{aligned}
& \mathrm{Y}_{\mathrm{t}}=\alpha_{0}+\sum \alpha_{\mathrm{i}} \mathrm{X}_{\mathrm{t}-\mathrm{i}}+\sum \beta_{\mathrm{j}} \mathrm{Y}_{\mathrm{t}-\mathrm{j}}+\mu_{1 \mathrm{t}} \\
& \mathrm{X}_{\mathrm{t}}=\lambda_{0}+\sum \lambda_{\mathrm{i}} \mathrm{Y}_{\mathrm{t}-\mathrm{i}}+\sum \delta_{\mathrm{j}} \mathrm{X}_{\mathrm{t}-\mathrm{j}}+\mu_{2 \mathrm{t}}
\end{aligned}
$$

And $\mathrm{F}$ test performed for the joint insignificance of the coefficients. The null hypothesis claimed that $Y_{t}$ does not cause $X_{t}$ or vice versa. Therefore, the rejection of null hypothesis indicates the presence of Granger causality. For each pair of variables two causality tests are performed so that it can be determined whether $X_{t}$ causes $\mathrm{Y}_{\mathrm{t}}$ or $\mathrm{Y}_{\mathrm{t}}$ causes $\mathrm{X}_{\mathrm{t}}$, or both or none.

\section{Tests of Stationary:}

Non-stationarity is a commonly observed problem in the analysis of time series. It seems from the fact that time series are not independent of time. When a variable is not stationary, its means and variances are not consistent overtime, and an observation is correlated with its more recent lags. Thus, a non-stationary series will exhibit a time varying mean and this is impossible to use the term 'mean' properly without referring to some particular time period.

In order to determine the cointegration between two or more series, two tests must be performed. First, it is necessary to test data series for non-stationarity, that is, to determine the order of integration. Secondly, data is examined for the evidence of a long run relationship between the variables in question.

\section{Unit Roots:}

Currently, the most widely used test for stationarity is a unit root in series is an indicator of stationarity. For this purpose, the Augmented Dickey-Fuller test has been used in the following format.

$$
\Delta Y_{t}=\varphi Y_{t-1}+\sum_{i=1}^{p} \alpha_{i} \Delta Y_{t-i}+\mu_{t}
$$

If the $\varphi$ turned out to be insignificant then the unit root exists in the series hence, the series is termed as nonstationarity. The lagged values of $\mathrm{y}_{\mathrm{t}}$ are added on the right hand side of the model to make the residual values purely white noise. The number of lagged values to be added in the model is determined by Akaike Information Criterion (AIC).

\section{Akaike Information Criterion (AIC):}

The Akaike information criterion is a measure of the relative goodness of fit of a statistical model developed by Akaike. It describes accuracy and complexity of the model. AIC is defined as:

$$
\mathrm{AIC}=2 \mathrm{k}-2 \ln (\mathrm{L})
$$

Where $k$ is the number of parameters in the statistical model and $L$ is the maximized value of the likelihood function for the estimated model. Given a set of candidate models for the data, the preferred model is the one with the minimum AIC value. Hence AIC not only rewards goodness of fit, but also includes a penalty that is an increasing function of the number of estimated parameters.

\section{Cointegration:}

Behind the concept of cointegration is the idea that variables hypothesized to be linked by some theoretical economic relationship should not diverge from each other in the long-run. Such variables may drift apart in the short-run but for an equilibrium relationship among such variables to exist the variables must not diverge without bound. Thus, 'Cointegration' is a statistical expression describing the nature of an equilibrium relationship where the divergence from a stable equilibrium is stochastically bounded and, when it does occur, it diminishes overtime. Cointegration allows us to describe the existence of equilibrium, or stationary relationship among two or more time series, each of which is individually non-stationary, if some linear combination of these series, which define the equilibrium relationship, has linear properties independent of time.

\section{Johansen Cointegration:}

The Johansen procedure is based on the maximum likelihood estimation in a VAR (Vector Auto Regressive) model. If we have a set of $k$ variables $(k \geq 2)$ which are integrated of first order I (1) and thought to be cointegrated, a VAR model with $\mathrm{k}$ lags containing these variables can be set up: Given a set of $\mathrm{K}$ time series variables $\mathrm{y}_{\mathrm{t}}=\left(\mathrm{y}_{1 \mathrm{t}},-----, \mathrm{y}_{\mathrm{Kt}}\right)$, the basic VAR model is of the form: 


$$
\mathrm{y}_{\mathrm{t}}=\mathrm{A}_{1} \mathrm{y}_{\mathrm{t}-1}+-------\mathrm{A}_{\mathrm{p}} \mathrm{y}_{\mathrm{t}-\mathrm{p}}+\mathrm{u}_{\mathrm{t}}
$$

$A_{i}$ are $(K \times K)$ coefficient matrix. This model is often briefly referred to as a VAR (p) process due to P number of lags.

For Johansen test to be used, the above VAR needs to be transformed into a Vector Error Correction Model (VECM) of the following form:

$$
\begin{gathered}
\Delta Y_{t}=\Pi Y_{t-1}+\Sigma_{i=1}^{k} \Gamma_{i} \Delta Y_{t-I}+\mu_{t} \\
\text { Where } \Pi=\left(\Sigma \beta_{\mathrm{i}}\right)-\mathrm{I}_{\mathrm{k}} \quad \text { and } \Gamma_{\mathrm{i}}=-\sum_{j=i+1}^{k} \beta_{j}
\end{gathered}
$$

This VAR model contains $\mathrm{k}$ variables in the first difference form on the LHS and k-1 lags of the dependent variables (differences) on the RHS, with $\Gamma$ coefficient matrix. As this test can be affected by the lag length used in the VECM, it is important to select the optimal lag length (AIC criterion).

Johansen test centers on an examination of the $\Pi$ matrix. In equilibrium, all the $\Delta \mathrm{Y}_{\mathrm{t}-1}$ will be zero and assuming error terms $\mu_{\mathrm{t}}$ to be at its expected value of zero, then $\Gamma_{\mathrm{i}} \Delta \mathrm{y}_{\mathrm{t}-\mathrm{I}}$ will be equal to zero. From this follows interpretation of $\Pi$ as a long-run coefficient matrix. The test of cointegration between the $\mathbf{Y s}$ is calculated by looking at the rank of the $\Pi$ matrix through its Eigen values. The number of Eigen values that are different from zero determines the rank of a matrix. There are two test statistics for cointegration under Johansen methodology: Trace $\left(\lambda_{\text {trace }}\right)$ Statistic and Max-Eigen value Statistic $\left(\lambda_{\max }\right)$. The test statistics are formulated in the following way:

$$
\begin{aligned}
& \lambda_{\text {trace }}(\mathrm{r})=-\mathrm{T} \sum_{r+1}^{k} \ln \left(1-\lambda_{i}^{\wedge}\right) \\
& \lambda_{\text {max }}(\mathrm{r}, \mathrm{r}+1)=-\mathrm{T} \ln \left(1-\lambda_{r+1}\right)
\end{aligned}
$$

Where $r$ is the number of cointegrating vectors under the null hypothesis $(r=0,1, k-1), k$ represents number of variables in the system, $T$ is number of observations and $\lambda_{\mathrm{i}}^{\wedge}$ is the estimated value for $\mathrm{i}^{\text {th }}$ ordered Eigen value obtained from the estimated $\Pi$ matrix.

$\lambda_{\text {trace }}$ is a joint test where the null hypothesis is that the number of cointegrating vectors is less than or equal to $r$ against the alternative hypothesis that there are more than $\mathrm{r}$.

$\lambda_{\max }$ conducts separate tests on every Eigen value and the null hypothesis that number of cointegrating vectors is $r$ against the alternative hypothesis $r+1$.

The cointegrating vector is not identified unless we impose some arbitrary normalization. E-Views adopt normalization such that the first $r$ series in the vector are normalized to an identity matrix. Hence, it gives us the normalized cointegrating relationship.

\section{Impulse Response Function:}

An impulse response function traces the effect of a one standard deviation shock to one of the innovations on current and future values of the endogenous variables. A shock to the $i^{\text {th }}$ variable directly affects the $i^{\text {th }}$ variable, and is also transmitted to all of the endogenous variables through the dynamic structure of the VAR. The impulse response functions can be used to produce the time path of the dependent variables in the VAR, to shocks from all the explanatory variables. If the system of equations is stable any shock should decline to zero, an unstable system would produce an explosive time path.

P.C Version of E-Views Econometric Package has been employed to analyse the data.

\section{Empirical Findings and Discussion: \\ Pair-Wise Causality:}

CPI is an important variable while discussing the macroeconomic stability in the economy. This variable dynamically affects many other macro variables and vice versa. So it is fruitful to study the causality among the relevant variables to have insight for further investigation. Since the variables discussed in this study may have two ways causation, hence, it is important to study the direction of the variables. The results of Granger Causality tests are presented in table-1. It has been established in the literature of monetary economics that money supply has direct and positive effect on the inflation in any economy. It is observed, obviously, that money supply determines the CPI; however the converse is not true. Since IIP works from the supply side and any up thrust to IIP may reduce the pressure of inflation. Moreover, IIP creates the demand in the economy also, hence expected to affect positively to the level of inflation. In the pair wise causality investigation IIP significantly affect the CPI. Besides, CPI variable works from the market side may discourage or encourage the production depending on the industrial segment we are dealing with, consequently we observed significant effect of CPI on IIP. Besides, imports also have significant affect on the CPI whereas the converse is not true. 
Table-1: Pair wise Granger Causality Tests

\begin{tabular}{|c|c|c|c|}
\hline Null Hypothesis & Obs. & $\begin{array}{c}\text { F- } \\
\text { Statistic }\end{array}$ & Probability \\
\hline LM3 does not Granger Cause CPI & 250 & $0.038^{*}$ & 0.050 \\
CPI does not Granger Cause LM3 & & 1.296 & 0.274 \\
\hline IIP does not Granger Cause CPI & 250 & $1.069^{*}$ & 0.045 \\
CPI does not Granger Cause IIP & & $12.967^{*}$ & 0.004 \\
\hline IMP does not Granger Cause CPI & 250 & $5.283^{*}$ & 0.005 \\
CPI does not Granger Cause IMP & & 2.717 & 0.068 \\
\hline
\end{tabular}

\section{Empirical Cointegration Analysis:}

The finding that many macro-economic time series may contain a unit root has spurred the development of the theory of non-stationary time series analysis. Engle and Granger, 1987 pointed out that a linear combination of two or more non-stationary series may be stationary. If such a stationary linear combination exists, the non-stationary time series are said to be cointegrated. The stationary linear combination is called the cointegrating equation and may be interpreted as a long-run equilibrium relationship between the variables.

In order to perform a cointegration test, the non-stationarity of the data series has to be established. Here, each variable is tested for unit roots using the Augmented Dickey-Fuller Test (ADF). Assuming the series have nonzero mean, a constant is included in the regression. Table- 2 summarizes the results of the ADF test. The critical values of the tests MacKinnon (1991) are used. Lag lengths are chosen according to Akaike Information Criterion (AIC).

Table-2 reveals that all unit root tests for the variables under the study have shown that test statistics are larger than the critical values and hence all the variables at levels are non- stationary. However, for the first difference series, the null hypothesis of a unit root is rejected for all the variables both at 1 and 5 percent levels of significance. Hence, the data series are stationary in the first difference and all variables are individually integrated of order one I (1).

Table-2: Augmented Dickey-Fuller (ADF) Unit Root Test (Stationary Test)

\begin{tabular}{|c|c|c|c|c|c|c|c|c|}
\hline \multirow[t]{3}{*}{ Variable } & \multicolumn{4}{|c|}{$\begin{array}{c}\text { In Level Form } \\
\text { (Random Walk with Drift) }\end{array}$} & \multicolumn{4}{|c|}{$\begin{array}{c}\text { In First Difference Form (Random Walk } \\
\text { with Drift) }\end{array}$} \\
\hline & \multirow{2}{*}{$\begin{array}{l}\text { ADF Test } \\
\text { Statistic }\end{array}$} & \multicolumn{2}{|c|}{$\begin{array}{l}\text { MacKinnon } \\
\text { Test Statistic }\end{array}$} & \multirow{2}{*}{ lags } & \multirow{2}{*}{$\begin{array}{l}\text { ADF Test } \\
\text { Statistic }\end{array}$} & \multicolumn{2}{|c|}{$\begin{array}{l}\text { MacKinnon } \\
\text { Test Statistic }\end{array}$} & \multirow{2}{*}{ lags } \\
\hline & & $1 \%$ & $5 \%$ & & & $1 \%$ & $5 \%$ & \\
\hline CPI & 4.09 & -3.46 & -2.87 & 1 & -6.74 & -3.46 & -2.87 & 2 \\
\hline LM3 & -0.35 & -3.46 & -2.87 & 1 & -11.99 & -3.46 & -2.87 & 1 \\
\hline IIP & -0.08 & -3.46 & -2.87 & 3 & -9.51 & -3.46 & -2.87 & 4 \\
\hline IMP & 2.12 & -3.46 & -2.87 & 1 & -12.69 & -3.46 & -2.87 & 1 \\
\hline
\end{tabular}

\section{Johansen Cointegration:}

Since, the unit root tests have determined the data series to be cointegrated of the same order I (1), Johansen's cointegration test can be applied. The determination of cointegration $r$ is concluded by using two statistics, the Trace Statistic $\left(\lambda_{\text {trace }}\right)$ and Max-Eigen Value Statistic $\left(\lambda_{\max }\right)$. A Vector Error Correction (VEC) model is a restricted VAR that has cointegration restrictions. The VEC specification restricts the long run behaviour of the endogenous variables to converge to their cointegrating relationships while allowing a wide range of short term dynamics. The cointegration term is known as the error correction term. 
The empirical results of the cointegration rank test derived from Johansen multivariate VECM involving the four variables chosen in the study are summarized in Table-3 \& 4. Trace statistic reveals that likelihood ratio statistic 53.867 for no cointegrating vector is larger than the critical values (both at $1 \%$ and $5 \%$ ) leading to conclude that null hypothesis of no cointegrating vector is rejected. Testing the hypothesis of at most one cointegrating vectors is accepted; the test statistic (19.491) is less than the reported critical values (Table-3). Max-Eigen value statistic and comparing with the critical values (Table-4) corroborates the earlier result of one cointegrating vector.

Table-3: Johansen Cointegration Test (Trace Test)

(January 1, 1992 to December 31, 2012, Monthly Data)

\begin{tabular}{|c|c|c|c|c|}
\hline Eigen Value & Likelihood Ratio & 5\% Critical Value & $\mathbf{1 \%}$ Critical Value & $\begin{array}{c}\text { Hypothesized No. } \\
\text { of CE(s) }\end{array}$ \\
\hline 0.1299 & 53.867 & 47.21 & 54.46 & None** \\
0.0502 & 19.491 & 29.68 & 35.65 & At most 1 \\
0.0253 & 6.758 & 15.41 & 20.04 & At most 2 \\
0.0017 & 0.424 & 3.76 & 6.65 & At most 3 \\
\hline
\end{tabular}

** denotes rejection of the hypothesis at $5 \%$ level of significance, LR test indicates 1 cointegration equation at $5 \%$ significance level

Table-4: Johansen Cointegration Test (Maximum Eigen Value Statistic) (January 1, 1992 to December 31, 2012, Monthly Data)

\begin{tabular}{|c|c|c|c|c|c|}
\hline Eigen Value & Likelihood Ratio & $\begin{array}{c}\text { 5\% Critical } \\
\text { Value }\end{array}$ & $\begin{array}{c}\text { 1\% Critical } \\
\text { Value }\end{array}$ & Null & Alternative \\
\hline 0.1299 & 34.37 & 27.07 & 32.24 & $\mathrm{r}=0$ & $\mathrm{r}=1$ \\
0.0502 & 12.73 & 20.97 & 25.52 & $\mathrm{r}=1$ & $\mathrm{r}=2$ \\
0.0253 & 6.33 & 14.07 & 18.63 & $\mathrm{r}=2$ & $\mathrm{r}=3$ \\
0.0017 & 0.424 & 3.76 & 6.65 & $\mathrm{r}=3$ & $\mathrm{r}=4$ \\
\hline
\end{tabular}

After ascertaining that at best a single cointegration relation among the selected variables, it is of interest to derive some useful perspectives from the sign condition and size of the coefficient in the long run cointegration relationship pertaining to variables. Since we are interested here in the CPI in relation to other variables, cointegrating vector normalized to CPI (Table-5).

Table-5: Normalized Cointegration Relations of Variables (January 1, 1992 to December 31, 2012, Monthly Data)

\begin{tabular}{|c|c|c|}
\hline Variable & Cointegration Coefficient & T-Statistic \\
\hline CPI & 1.00 & - \\
LM3 & 76.95 & 26.18 \\
IIP & -12.13 & 36.02 \\
IMP & 0.48 & 1.69 \\
Constant & -0.79 & 2.08 \\
\hline
\end{tabular}


LM3 money supply variable bears a positive and highly significant coefficient corroborates the theory that CPI is positively affected by the levels of money in circulation. However, as theory states that supply may have inflation reducing impact has been vindicated by negative and significant coefficient attached to the IIP. Though, India imports commodities which may have considerable affect on the Indian inflation has been reflected with mix results. IMP variable bears positive but insignificant coefficient, however this variable is significant at $10 \%$ level of significance, hence, the role of this variable cannot be denied thus far its relation with Indian inflation is concerned. One important feature of Indian inflation is reflected in the normalized cointegration equation is that constant term is negative and significant. Meaning thereby, apart from economic variables, inflation may be reduced by using the moral suasion. People should be adequately educated towards their buying habits.

\section{Vector Error Correction:}

The foregoing discussion has highlighted cointegrating relationship exists among the selected variables. The inclusion of such error correction terms exclusively in the VAR system, the estimated equation for CPI in VAR along with cointegration component is presented in the box given below.

\section{The ECM Equation of CPI:}

$$
\begin{aligned}
& \Delta \mathrm{CPI}=0.453+0.0025^{*} \mathrm{Z}_{\mathrm{t}-1}+0.28^{*} \Delta \mathrm{CPI}_{\mathrm{t}-1}-0.003 \Delta \mathrm{CPI}_{\mathrm{t}-2}+0.41^{*} \Delta \mathrm{LM}_{\mathrm{t}-1} \\
& \begin{array}{llll}
(5.32) & (2.76) \quad(4.41) & (0.04)
\end{array} \\
& +0.075^{*} \Delta \mathrm{LM}_{\mathrm{t}-2}-0.013 \Delta \mathrm{IIP}_{\mathrm{t}-1}-0.032^{*} \Delta \mathrm{IIP}_{\mathrm{t}-2}+0.005^{*} \Delta \mathrm{IMP}_{\mathrm{t}-1}+0.004 \Delta \mathrm{IMP}_{\mathrm{t}-2} \\
& \begin{array}{lllll}
(1.98) & (0.99) & (2.61)
\end{array} \\
& \mathrm{Z}_{\mathrm{t}-1} \text { is cointegrating component, } \quad \mathrm{R}^{2}=0.38 \quad \mathrm{~N}=249 \quad \mathrm{~F}=5.65 \text { (Significant) } \\
& \text { Figures in parentheses are } \mathrm{T} \text { values } \quad * \text { indicates the significant values }
\end{aligned}
$$

First difference of CPI is significantly influenced by the fact of long term equilibrating relationship among the variables. Inflation in the present period is significantly influenced by the inflation in the previous period, however such impact wanes subsequently. Change in money supply has positive and significant impact on the changes in inflation levels and persist for some more time however, with declining strength. However, changes in IIP have negatively affected the change in inflation levels but this could become effective after a gap of one time horizon. Undoubtedly, as expected the import index positively affect the inflation change contemptuously and weaken in the subsequently periods. To vindicate such dynamism in the CPI variable in VAR model the Variance Decomposition and Impulse Response Functions is used in the subsequent section.

\section{Impulse Response Function (IRF):}

Apart from the long and short term dynamics, VEC model of selected variables is useful for identifying the relative importance of each variable to others, based on the dynamic interaction among them through impulse response functions (IRF). This is useful for estimating the importance of innovations in one variable to other variables and the nature of transmission across variables. IRF traces the impact of one standard deviation change in exogenous variable on the endogenous variable. The impulse response functions can be used to produce the time path of the dependent variables in the VAR, to shocks from all the explanatory variables. If the system of equations is stable any shock should decline to zero, an unstable system would produce an explosive time path. 
Figure-1: Response to One S.D. Innovations
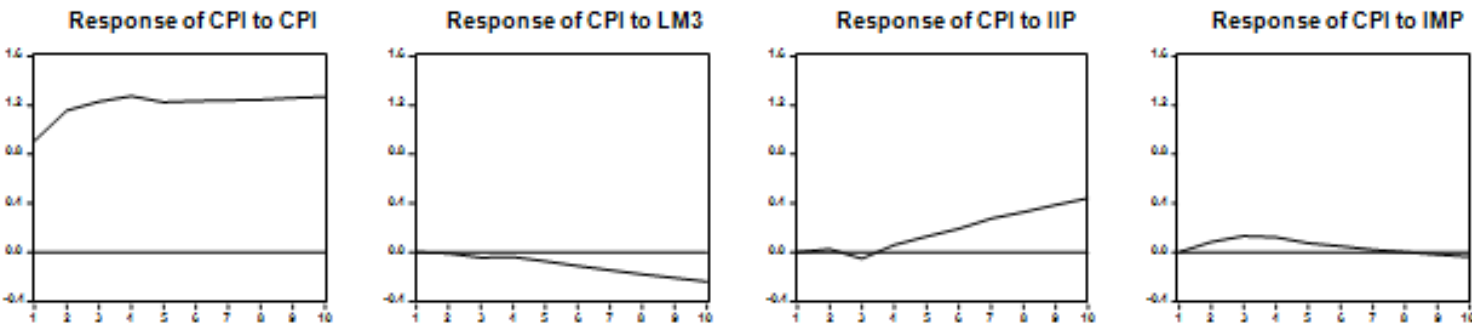

Figure-1reveals the response time path of the CPI variable to the one standard deviation innovation to the variables in the VAR system. The response of CPI to CPI shows that it responds positively up to three time horizons and subsequently it stays there. One standard deviation innovation to the LM3 variable does not put significant pressure on the CPI and even after three time horizons it declines. Impulse response of CPI to IIP variable is that after three time horizons it has explosive effect on inflation may be due to as a demand pull factor. Impulse of one standard deviation to IMP index is positively reflected in CPI and subsequently this effect weakens and dies down. We may conclude here that CPI bears stable relationship with CPI and Imp index however such relation is unstable with money supply and IIP.

\section{Concluding Remarks}

This study based on the monthly data between 1992 and 2012, is an endeavor to study the inflation dynamics in the Indian economy by employing cointegrated autoregressive technique. Inflation variable has cointegrating relationship with other macro economic variables. It has been established that money supply is most important variable in explaining the variation in inflation overtime. Moreover, import index variable also matter for inflation in Indian economy but with considerably lesser strength. IIP, as expected, has inflation discouraging affect. Besides, apart from the economic variables, moral suasion factor has also been proved to be important in controlling Indian inflation. That is, people should be adequately educated about their buying habits. Cointegrating relationship among the variables has considerable bearing on the inflation dynamics. Moreover, inflation bears stable and correcting relationship with CPI and import index variables, however such relationship is unstable and explosive with money supply and IIP.

\section{References}

[1] Bishnoi T. R. and Koirala T. P. (2006): "Stability and Robustness of Inflation Model", Journal of Quantitative Economics, Vol. 4 (2), 114-130.

[2] Callen T. and Changl D. (1999): "Modeling and Forecasting Inflation in India", IMF Working, WP / 99 /119.

[3] Deshpande A. and Sarkar P. (1995): "Structural Adjustment in India: A Critical", Economic and Political Weekly, Vol.30 (49), 3151-3155.

[4] Domac I. \& Carlos E. (1998): “The Main Determinant of Inflation in Albania", World Bank Policy Research, Working Paper No. 1930.

[5] Fisher Irving (1911): “The Purchasing Power of Money: Its Determination and Relation to Credit, Interest, and Crises”, Macmillan (New York).

[6] Gary G. Moser (1995): "The Main determinants of Inflation in Nigeria", IMF Staff Papers, Vol. 42 (2), $270-289$.

[7] Janak Raj et. al. (2008): "Imported Inflation: The Evidence from India”, Reserve Bank of India Occasional Paper, Vol. 29 (3).

[8] John R. M. (2003): "Inflation in India: An Analysis Using Post Liberalized Data", IGIDR Working Paper No.

[9] Lim C. \& Adedeji O. S. (2000): “An Econometrics Analysis of the Determinants of Inflation in Turkey, IMF Working Paper, $97 / 170$.

[10] Mosayed P. \& Mohammed R. (2009): "Sources of Inflation in Iran: An Application of the Real Approach", International Journal of Applied Econometrics and Quantitative Studies, Vol.6 (1), 61-76.

[11] Pandit V. (1993): “Controlling Inflation: Some Analytical \& Empirical Issues", Economic \& Political Weekly, Vol.28 (1), $39-42$.

[12] Patra D. \& Partha R., (2010): "Inflation Expectations and Monetary Policy in India: An Empirical Exploration", IMF Working Paper, WP/10/84.

[13] Sahadudhen I. (2012): "A Cointegration and Error Correction Approach to the Determinants of Inflation in India", International Journal of Economic Research, Vol.3 (1), 105-112.

[14] Srinivasan, N., V. Mahambare \& M. Ramachandran, (2006), "Modelling Inflation in India: A Critique of the Structural Approach", Journal of Quantitative Economics, Vol. 4 (2), 45-59.

[15] www.mospi.gov.in

[16] www.rbi.org.in 